\title{
LETTERS
}

\section{Semantics in referring for medical assistance in dying}

The title "Doctors do not need to refer for medical assistance in dying" for the editorial $^{1}$ in the emailed list of contents for the February 20, 2018, issue is misleading. Physicians, at least in Ontario, do need to refer for medical assistance in dying (MAiD), so, as the article notes, says the Ontario Superior Court of Justice.

The religious rights of all Canadians are protected, but the right to a particular occupation is not. If a person's religious beliefs are incompatible with facilitating patients to access any legal service that is compatible with their beliefs, than they have the option of choosing a different occupation.

I cannot imagine why anyone would find giving the patient information about MAiD and the phone number of the coordination service acceptable when providing a referral is not. I disagree with you; this is semantics.

\section{Eric Brown MD}

Anesthesiologist, Grey Bruce Health Services - Owen Sound, Owen Sound, Ont.

Cite as: CMAJ 2018 June 4;190:E692.

doi: $10.1503 / \mathrm{cmaj} .69260$

\section{Reference}

1. Kelsall D. Physicians are not solely responsible for ensuring access to medical assistance in dying. CMAJ 2018; 190:E181.

Competing interests: None declared. 